\title{
Identification of Operational Issues at a Switchgear Manufacturing Company: A Case study
}

\author{
Aswathi. ${ }^{1}$, Ciby Thomas ${ }^{2}$ \\ ${ }^{I}$ M.Tech Industrial Engineering and Management, Rajiv Gandhi Institute of Technology, Kerala, India \\ ${ }^{2}$ Associate professor, Department of Mechanical Engineering, Rajiv Gandhi Institute of Technology, India
}

\begin{abstract}
The Aluminium Industries Ltd was one of the leading switchgear manufacturers in India. It flourished in late 1960's. The company then faced severe financial stringency and doomed in 1985. This paper is based on an industrial training carried out at the company. The performance analysis and problem identification were carried out as part of the study and is summarised through this paper. The real problems at the company could be identified and suitable corrective measures could solve the problem and upheld the company in future.
\end{abstract}

Keywords - Capacity utilization, Cause and Effect relationship, Financial Performance, Sales performance SWOT analysis

\section{INTRODUCTION}

As part of the M.Tech degree program a 75 days Industrial training was carried out at the Aluminium Industries Limited, Switchgear Division, Mannar from 10th October 2012 to 31st January 2013. This paper has been solely prepared from the training that was done at ALIND.

The ALIND is one of the pioneer companies in switchgear industry which flourished in 70's and 80's. But later in 1985 the company suffered severe financial crisis and was doomed. My inquisitive mind to understand the real causes of its failure from an Industrial engineer perspective led me to ALIND.

\subsection{Methodology}

The study about the organization was done by direct observation of the functioning of the plant, discussion with managers and workers, going through the log books, manuals and brochures of the company. The website of the company was also referred for getting data.

Data was collected from primary as well as secondary sources. Primary sources included discussions and interviews with managers and workers of the company and directly observing the functions of the company. Secondary sources of data include Company documents, manuals and websites.

\section{CASE STUdY: ALIND SWITCHGEAR Division, MaNNAR}

The Aluminium Industries Limited came in to existence on 2nd January 1946, promoted by the Seshasayee group with conductor division set up in Kundara, Kerala under technical collaborations with the world renowned ALLAN Canada, The Aluminium development Laboratories UK and ALLAN SA, Zurich, Switzerland. Since then ALIND has produced more than a million kilometers of AAC, ACSR, and AAAC conductors building the lifelines of power in India and abroad. Hence ALIND could rightly call itself THE POWER MOVERS.

Presently ALIND with its corporate office in Mumbai has manufacturing units located in 3 statesKerala, Orissa and Andhra Pradesh, manufacturing cables and conductors, steel wires, wire making machineries, high voltage switchgears and static relays. ALIND became the largest manufacturer of cables and conductors in India. ALIND has fully fledged export activities which coordinate the export activities of the entire company and its products group operating from the corporate office at Trivandrum. Since 50's ALIND has exported conductors, cables, wires and cable making machinery, switchgears, relays etc to thirty countries around the world.

\subsection{PRODUCT PROFILE}

The main product of ALIND is Circuit Breaker. The various types of products available at ALIND are $\checkmark \quad 25 \mathrm{KV}$ (52KV class) single pole interrupters/breakers for railways. 


\section{Performance Analysis}

3.1 PRODUCTION PERFORMANCE

The production details of past six years were collected and presented in Table 1.

Table 1:- Production over years

\begin{tabular}{|c|c|}
\hline Year & Production (No.) \\
\hline $2006-2007$ & 620 \\
\hline $2007-2008$ & 521 \\
\hline $2008-2009$ & 748 \\
\hline $2009-2010$ & 850 \\
\hline $2010-2011$ & 500 \\
\hline $2011-2012$ & 450 \\
\hline $2012-$ Dec 2012 & 350 \\
\hline
\end{tabular}

The plant has been installed with a production capacity of 1200 breakers per year. The details of production are given above. From the table it is clear that the production is decreasing considerably over the years. The production was higher in 2009-10 but it decreased then on and reached 350 by Dec 2012.The fig 1 shows the trend of production. From the graph (Fig 1) it is clear that from 2007 to 2010 the production kept increasing and after 2010 there was a sudden decline in the trend.

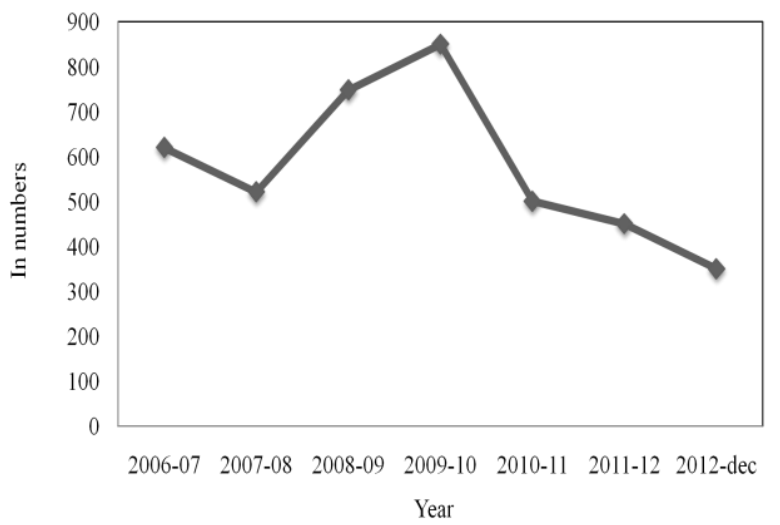

Fig 1:- Production over years

From 2006 to 2007 also the production had been decreasing, the reason for this declining trend then was bank freezing, due to which further production had to be stopped. Similarly in 2010 with peak production there had been a severe financial crisis due to fund collection problem. The major issue that could be identified was the financial problem.

\subsection{SALES PERFORMANCE}

The sales figures collected are given below in table 6 . The production and sales are proportionate as the company follows make to order policy that is they produce only as per the customer order.

Table 2:- Sales over years

\begin{tabular}{|c|c|}
\hline Year & Sales( in crore) \\
\hline $2007-2008$ & 9.11 \\
\hline $2008-2009$ & 12.71 \\
\hline $2009-2010$ & 13.91 \\
\hline $2010-2011$ & 10.37 \\
\hline $2011-2012$ & 7.38 \\
\hline
\end{tabular}

Even though the company does not go for any marketing activities like advertisement, sales promotion through Medias there is always a higher demand for their products, as they are approved by RDSO. 


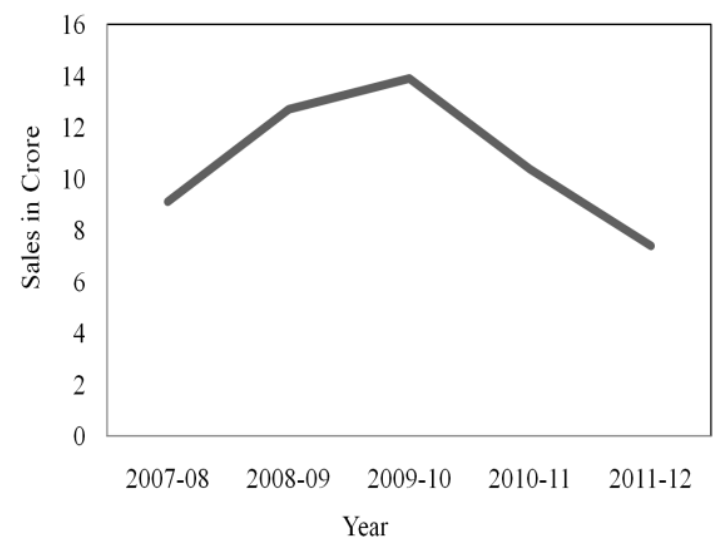

Fig 2:- Sales over years

The entire demand could not often be met due to financial issues at the firm. The raw materials are purchased on credit and unless they make some payments further supply will be stopped and that badly affects the production. From the table it is clear that the sales were also higher in 2010 than any other years. The graph is shown in fig 2.The sales follow the same trend as that of the production graph. Over the years the sales is decreasing steadily. From the graph it is well clear that the sales have been increasing till 2010 and then on it started decreasing considerably over the years.

\subsection{CAPACITY UTILISATION}

Capacity utilization is a concept in economics and managerial accounting which refers to the extent to which an enterprise or a nation actually uses its installed productive capacity. Thus, it refers to the relationship between actual output that 'is' produced with the installed equipment and the potential output which 'could' be produced with it, if capacity was fully used. Capacity utilization rate is also an indicator of how efficiently the factors of production are being used. The details of capacity utilization are as given in table 3 .

$$
\text { Capactity utilisation }=\frac{(\text { Actual production }) * 100}{(\text { Installed capacity })}
$$

Table 3:- Capacity utilization

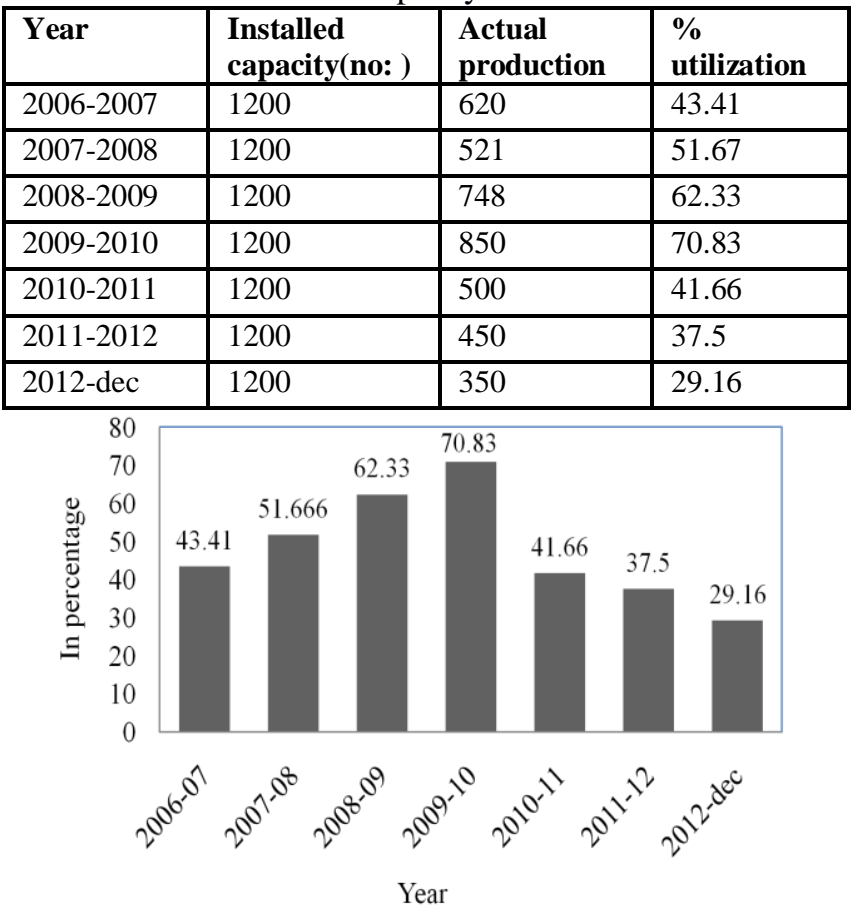

Fig 3:- Capacity utilization graph

From the table it can be inferred that there is bare minimum utilization of the installed capacity. The capacity utilization had been high during 2009-10 and later it decreased to 30\%. From 2006 to 2010 it had been 
gradually increasing, and the reason for decline thereafter is the severe financial stringency the firm had been suffering. The graph is shown in Fig. 3.

From the graph it is clear that the capacity utilization is also showing a declining trend. The capacity utilization is below 50\%, that is there is an under utilization of capacity. This is only due to the financial problem.

\subsection{FINANCIAL TURNOVER}

Companies desire a fast or high turnover, as this indicates financial health. Turnover means the revenues earned by a company from its normal operations whether good or services. The financial turnover from the financial statements is shown in Fig 4.

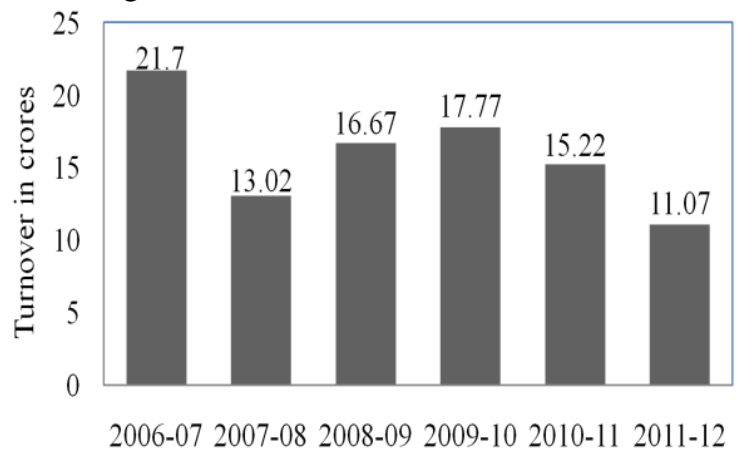

Year

Fig 4:- Financial turnover plot

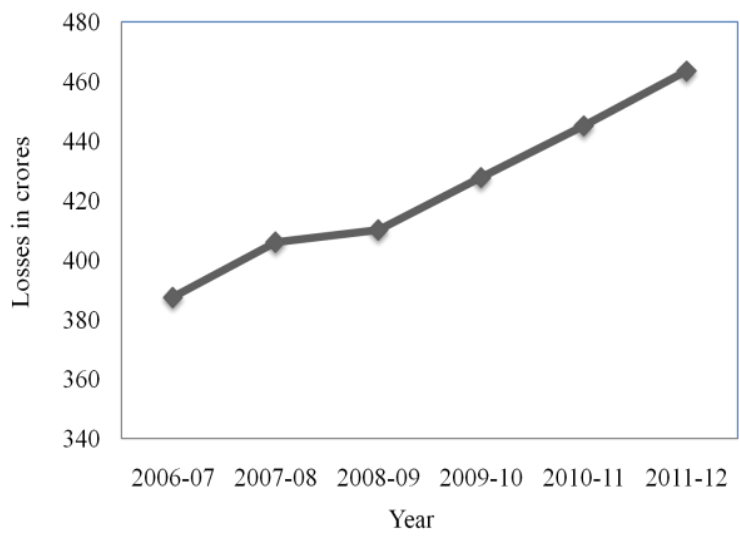

Fig 5:- Financial losses accumulated

From the plot of financial turnover it can be observed that all the graphs so far shown follow the same trend. That is they keep increasing till 2009-10 and decrease then on. The graph of financial losses is shown in Fig 5.

From the above two figures it is clear that the financial health of the firm is poor. The turnover of the firm is decreasing and the losses are getting accumulated. The accumulated losses have reached 463.53 crore last year as per the accounting statements. The liquidity, profitability and debt paying abilities are all poor as far as ALIND is considered.

\subsection{METHODOLOGY ADOPTED}

\section{SWOT Analysis at ALIND}

The SWOT analysis was done by analyzing the data collected from the firm, by direct observation, interviews, secondary sources etc. The valuable experience and guidelines of employees and managers came as an aid, in giving final shape to the analysis part. Firstly my focus was to classify collected data based on the following questions in mind:

- What this organization can do? (Strength)

- What this organization cannot do? (Weakness)

- What are the potential favorable conditions for this organization? (Opportunities)

- What are the potential unfavorable conditions for this organization? (Threats) 
After this, with the rough analysis in mind, the managers and employees were approached and further details were collected by using an unstructured questionnaire and by using this information, the final analysis was done.

\subsection{STRENGTHS}

\section{$>$ ISO certified company}

ALIND is an ISO 9001-2008 certified company

$>$ Quality product

It produces quality and reliable products which offer trouble free operation for more than 30 years

$>\quad$ RDSO approved C.B

The product is approved by RDSO and has also qualified the Type test at Central Power Research Institute, Bangalore.

$>$ Well designed layout

The company was set up with French collaboration and its layout was designed by Alsthom, France.

\subsection{WEAKNESSES}

\section{* Outdated technology}

The company employs outdated technology in certain production process like moulding. The epoxy resin moulding can be replaced with cross linked polymer sleeves

\section{* Poor capacity utilization}

Even though the company is installed with a capacity of 1200 breakers per year, the percentage utilization of plant capacity is below average

\section{* Inefficient planning dept}

The planning department comprises of only one staff, and that is strongly affecting the entire works at the plant.

\section{* Employee shortage} trainees

Presently there is no fetching of new employees and if at all it affects the production, that they employ

* Poor working environment

There is frequent conflict between the labor unions

* Poor maintenance

The ageing of machines results in frequent breakdown and the company fail to provide any preventive maintenance

* Poor marketing strategy

The company has poor marketing strategy

\subsection{OPPORTUNITIES}

\section{- Product diversification}

There is a greater opportunity to exploit at ALIND. Presently the company focus on only two products, but it was designed for production of more than 8 products of different classes.

- Adoption of new technology

The moulding process employed at company is the only bottle neck process and is capable of producing only 3 vacuum bottles per day.

\section{Use of CNC machines}

The conventional lathe available at the plant can be replaced by $\mathrm{CNC}$ lathes which saves time and cost.

口 Export

Export would be better opportunity. There are many countries whose markets have a high potential due to increasing demand. Such markets can be effectively tapped.

\subsection{THREATS}

\section{- Healthy competitors}

The competitors of ALIND are all giant companies which have flourished in Electrical industry.

- BIFR control

The control of BIFR is the real threat of the company. The share holders have no control over the assets.

The promoter which took over the company makes no efforts to uplift the company from financial sickness

- Absence of bank facilities

Because the company is declared SICK, it does not enjoy any bank facilities unlike other firms 


\section{PROBLEM IDENTIFICATION}
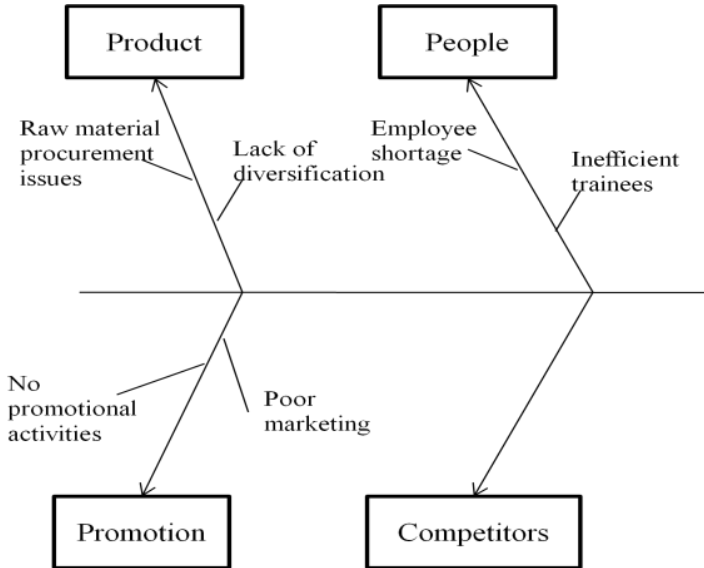

Fig 6: Cause and Effect Diagram

When we analyze minutely, we can arrive at the culmination of the SWOT analysis. As mentioned in the performance analysis, the production of the firm is not in a position to tap the positive growth shown by the sector. This results in the loss of market share of the firm. When we try to list the causes of this issue, we can find so many internal and external factors responsible, as shown in the fish-bone diagram above.

The ultimate effect is low market share. The factors causing this effect are the productivity issues like absence of maintenance, power supply issues and employee shortage, absence of promotional activities, strong competitors, liberal credit policy, raw material procurement issues and so on. At present due to poor financial condition of the firm, it is difficult to rectify any of these problems.

\subsection{FINDINGS}

\section{Findings And Suggestions}

1. The main strength of the company is its product itself. Only 4 companies CB's have passed the type test at CPRI, Bangalore and ALIND is one among those.

2. It is approved by RDSO also, and hence almost all contracts of Railway are given to ALIND. About $60 \%$ of Railway contracts are awarded to ALIND. Even though there are various other switchgear manufacturers in India they haven't qualified these tests.

3. Aged machines lead to frequent breakdown which affects the production. The machines at ALIND were installed in 1969. Because of the absence of a maintenance department preventive maintenance is not offered, which affects the machine productivity adversely. Also to repair a down machine an external mechanic had to be called.

4. Unavailability of raw materials is another problem due to which demands are not often met on time. The timely availability of raw materials is often hindered by the severe financial crisis the firm is suffering. Because the raw materials are purchased on credit, the supplier asks for some payments to clear some pending dues. Unless the firm pays this amount the material will not be supplied.

5. The working environment is poor because of the frequent conflicts between the labor unions, and it often affects the production also. The labor unions favouring and opposing the management leads to frequent disputes at the firm, due to which the plant had to be shut for many days.

6. Under utilization of the installed capacity. The production with respect to the installed capacity is very poor, and it has decreased to $29 \%$ by December 2012.

7. Poor marketing strategy. The company does not follow any marketing strategies. No promotional activities are undertaken, due to which it does not reach many of the industrial customers.

8. The conventional moulding technique employed is a bottle neck as it produces only three breakers per day

\subsection{SUGGESTIONS}

1. Fetching of new employees would solve the severe employee shortage problem

2. The conventional vacuum moulding technique employed at the firm may be replaced by cross linked polymer sleeves, which can produce more number of breakers.

3. The down time of the compressors are too high, and it affects the production. Presently there is no frequent maintenance employed. A good maintenance department may solve this problem.

4. The employees need to be motivated through various training programs. No training programs have been offered so far.

5. Better work planning and scheduling techniques to be installed 
6. The non core activities like spot blasting and painting may be sub contracted, which saves cost.

7. Marketing efforts to be strengthened

\subsection{LIMITATIONS OF THE STUDY}

1. Time

The time period available was a major limitation of the study since the time was limited to a period of 75 days. This was allotted to visit and study the different departments and units. The detailed study on many units demands more time period.

\section{Accuracy of the data}

The study is mainly based on secondary sources and therefore errors are possible. The personal interview may be affected by personal bias. The personnel resource of the data management section in the company is limited and there was often limited documentation in the unit, due to the centralized nature of management in certain aspects, e.g. purchase, sales etc. So it was a challenge to collect data without interrupting the normal operation of the company, at the same time, there was limited scope for ensuring accuracy of the collected data.

\section{Conclusion}

From the detailed study about the organization profile, productions processes, performance analysis and SWOT analysis we can infer that ALIND is an underperforming firm. ALIND is a private limited company with 86 employees. On analyzing the different performance measures it was found that the company is performing below average, with less than $30 \%$ capacity utilization. Also the company suffers severe financial stringency and the accumulated losses accounts for 463 crores as per the accounting statements of 2011-2012. Various problems could be identified of which lack of maintenance services and employee shortage were the critical issues. A good maintenance department may be set up at the plant. Also employee shortage issue to be addressed

\section{Acknowledgements}

I thank almighty for all the blessings and guidance he has offered through many.

\section{Reports}

\section{REFERENCES}

[1] Annual Report of ALIND 